\section{FREQUENCY AND TYPE OF FRACTURES ENTERING THE EMERGENCY UNITS OF ORTHOPEDIC HOSPITALS}

\section{ABSTRAC}

BACKGROUND

Trauma is globally encountered in the emergency department on regular intervals placing a burden on the economy through an increase in the mortality

OBJECTIVE

The aim of the study is to assess different types of fracture entering the emergency department, the risk of these froctures and also to find the association

\section{STUDY DESIGN AND SETTINGS}

A Cross sectional survey was conducted on 450 participants in differen

\section{RESULT}

Karachi. Road Treffic that fracture cases are increasing in emergencies in fracture whereas fall or slip iniuries and brawl/fight show $22.2 \%$ and $147 \%$ felly alcohol and cigarette smaking has adverse effect $91.6 \%$ population revealed no relationship. Regional distribution of fracture shows lower limb fracture with $40.9 \%$ as most commonly occurring fractures where male percentages is higher than females. The selected population age commonly.
Keywords

Wents, Trauma, Emergency Department, Violence, Fall, Upper Extremity, Lower Extremity

\section{Pawan Rekho}

Ziauddin College of Physical Therapy pawanrekha08@yahoo.com

\section{Sheena Kumari}

Ziauddin College of Physical Therapy Ziauddin University
drsk marhi@yahoo.com

Amna Aamir Khan

Ziauddin College of Physical Therapy

zlauddin University akhan39@caledonian.ac.uk

[Rekha P, Kumari S, Khan AA. entering the Emergency Units Orthopedic Hospitals. Pak. j. rehabil. 2013;2(2):21-26]

\section{NTRODUCTION}

Trauma, the leading cause of mortality is globally encounth United States (US) it is considered as the larding causs of death for those under the age of 35 and accounts for 10 percent of all deaths between both men and women? In addition, injuries from accidental trauma worldwid leave over 45 milion people each year wilh moderate to more than 50 million patients. It also accounts for admission of approximately 30 percent of patients in al

In the first national injury survey in Pakistan, revealed the 41 injuries for every 1000 person $5^{5}$. Thy was found to identified Road Traffic Injuries (RTA) as one of the major causal factors for injury presenting to emergency. Moreogrowing number of elder population is also contributing to life time disability. Road traffic injuries have a yearly ncidence of 15 injuries for every 1000 persons $s^{5}$. It has been accident tend to have uneducated mothers when compared to non-injured controls. In addition to the road traffic accident violence plays an essential role also intimate partner vehemence to war. Researchers have been keen to assess the magnitude of intimate partner violence in Pakistan on multiple occasions. It has been indicated that $44 \%$ of women experience lifetime marita physical abuse\%. During 58 bomb blasts in this city alone has been repor ed, resulting in 689 injuries and 164 deaths resulting in several musculoskeletal problems and disabilities ${ }^{8}$.

These injuries comprise of approximately 12 percent of Departments $(E D)^{9}$ ve visits to US pediatric Emergency causing considerable cost and morbidity for the children. Despite of aggressive campaigns for injury prevention
the overall rate of fractures has been increasing I.1.11 $^{1.11}$ and approximately half of all children would fracture a bon during childhood ${ }^{12}$. It has been observed and documented that the periosteal of pediatric bone has significan bolically active, thicker, and stronger than the metaWhich limits in fracture displacement, reducing the ikelihood of open fractures, and maintaining stability ${ }^{13.4}$. These qualifies and function of periosteal are responsible greenstick, and plastic deformation (or bowing $\left.\right|^{13.151 .6}$.

However Upper extremity fractures in adults are also documented on high account in approximately 2 millio percent of the visits are for humeral fractures: 31 percen or radial /ulnar fractures; and 51 percent for carpal. metacarpal, or phalangeal fractures. Interestingly, fal has been acknow
extremity fractures

No significant work has been conducted to assess the requency of different types of fractures entering the mind the cosmopolitan status of the city it is imperg that research leading to the beneficial in identification of common fractures and improvising the preliminary care should be given in these scenarios.

\section{MATERIALS AND METHODS}

Study Design

sudy was conducted in tertiary care chi by year survey anter the sample of convenience was used to collect the data was collected by two therapists by personal interview. It was

Inclusion/Exclusion Criteria

All the conscious patients entering the ED were selected for the study. These patients represented of single aged patients were completed by their guardians and representatives. The patients on ventilators, with blast injuries cases were excluded from the study as most of non-responsive to questions or multiple and others are were excluded from the study.

\section{Data Collection Procedure}

384 subjects were included in the study for which the which was taken at $50 \%$ because no relevant data was available. The bound of error has been taken at $5 \%$ with $95 \%$ of confidence. Asit was a cross-sectional survey so in sample size is inflated to 450 , to exclude non-response and incompletely filled questionnaires.

The questionnaires were administered to the 450 particidemographic information such as (age, gender, and occupation). While filling the interview based questionnaire the medium of language was taken into account to be easily understandable to both the researcher as well ambience.

All participants personal details such as area of residence fracture history fon any disease and previous fracture was used to audit the frequency of fracture. The RTA by vehicles included both the drivers and passengers whereas others involved fall slip. The trauma caused by patholomented in the avestionnair Fractures resulting from domestic violence were also included. The study also checked to see the effect of alcoholism and smoking on variables were incop and

\section{Data Analysis Procedure}

Data was entered using the SPSS version 20. Before the

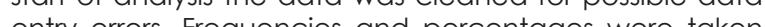
out for categorical variables. Association bo gender and type of fracture was assessed through application of Chi Square test.

\section{RESULTS}

A total of 450 cases of fracture were assessed during 12 moniths of period with $79.6 \%$ males and $20.4 \%$ of females The average age is documented to be 35.8 years. 


\begin{tabular}{|c|c|}
\hline Gender & $\mathrm{n} \%$ \\
\hline Male & $358(79.6)$ \\
\hline Female & $92(20.4)$ \\
\hline $\mathrm{N}$ & 450 \\
\hline \multicolumn{2}{|c|}{ Table 1: Represents the gender associated with } \\
f
\end{tabular}

Table 1: Represents the gender associated with fracture

The questionnaire basically focused on the region and type of fractures and the results are summarized in Table
2. It was noted that $40.9 \%$ of fractures were of lower limb whereas vertebral fractures were only $8.2 \%$. The estimated percentage of simple fracture among both the
gender was $49.1 \%$. Fracture of other types such a displaced, open communicated and spinal in tota occurred only $0.8 \%$ in the ED. Compound fracture 135 (30\%) and hairine fracture $90(20 \%)$ were also noted Interestingly, only
fracture history.

Interestingly, drivers/labors, women and students were Among 92 women $56 \%$ of women were noted to be housewives.

\section{Fracture Region}

\begin{tabular}{|c|c|}
\hline \multicolumn{2}{|l|}{ Fracture } \\
\hline & $\mathrm{n}(\%)$ \\
\hline Lower Limb & $184(40.9)$ \\
\hline Skull Fracture & $51(11.3)$ \\
\hline Upper Limb & 178 (39.6) \\
\hline Vertebral Fracture & $37(8.2)$ \\
\hline $\mathrm{N}$ & 450 \\
\hline \multicolumn{2}{|c|}{ Fracture Type } \\
\hline Compound Fracture & $135(30)$ \\
\hline Displaced Fracture & $2(0.4)$ \\
\hline Hairline Fracture & $90(20)$ \\
\hline $\begin{array}{l}\text { Open Communicated } \\
\text { Fracture }\end{array}$ & $1(0.2)$ \\
\hline Simple Fracture & $221(49.1)$ \\
\hline Spiral Fracture & $1(0.2)$ \\
\hline $\mathrm{N}$ & 450 \\
\hline
\end{tabular}

\begin{tabular}{|l|l|}
\hline Multiple Fracture & $131(29.1)$ \\
\hline Singe Fracture
\end{tabular}

\begin{tabular}{|c|c|}
\hline Single Fracture & $319(70.8)$ \\
\hline$N$ & 450 \\
\hline
\end{tabular}

\begin{tabular}{|c|c|}
\hline $\mathrm{N}$ & 450 \\
\hline \multicolumn{2}{|c|}{ Fracture History } \\
\hline Yes & $88(19.5)$ \\
\hline No & $362(80.40)$ \\
\hline $\mathrm{N}$ & 450 \\
\hline
\end{tabular}

\begin{tabular}{cc}
$\mathrm{N}$ & 450 \\
\hline Table 2: Represents the region, type and numbers
\end{tabular}

fracture and history of fracture
The prevalence of Road Traffic Accident was noted to be highest in both the genders $48 \%$ as compared to other factors of fractures. Marked difference was observed and rilhay track $0.2 \%$ yet maket fractures we 0 still experiential $10 \%$.

\begin{tabular}{|c|c|}
\hline \multicolumn{2}{|c|}{ Place of Fracture } \\
\hline \multicolumn{3}{|c|}{$\mathrm{n}(\%)$} \\
\hline Home & $117(26)$ \\
\hline Gym & $3(0.7)$ \\
\hline Market & $45(10)$ \\
\hline Office & $10(2.2)$ \\
\hline Other & $47(10.4)$ \\
\hline Railway Track & $1(0.2)$ \\
\hline Road & $216(48)$ \\
\hline School & $11(2.4)$ \\
\hline Table 3: Shows the place of injury \\
\hline
\end{tabular}

\begin{tabular}{|c|c|c|c|c|}
\hline & & \multicolumn{2}{|c|}{ Gender } & Total \\
\hline $\begin{array}{l}\text { Fracture } \\
\text { Type }\end{array}$ & & Male & Female & \\
\hline \multirow{2}{*}{ Compound } & Count & 106 & 29 & 135 \\
\hline & $\begin{array}{l}\text { \% within } \\
\text { Gender }\end{array}$ & 29.60 & 31.5 & $30.0 \%$ \\
\hline \multirow{2}{*}{ Displaced } & Count & 0 & 2 & 2 \\
\hline & $\begin{array}{l}\text { \% within } \\
\text { Gender }\end{array}$ & 0.00 & 2.20 & $0.40 \%$ \\
\hline \multirow{2}{*}{ Hairline } & Count & 74 & 16 & 90 \\
\hline & $\begin{array}{l}\text { \% within } \\
\text { Gender }\end{array}$ & 20.70 & 17.4 & 20.0 \\
\hline \multirow{2}{*}{$\begin{array}{c}\text { Open } \\
\text { Communicated }\end{array}$} & Count & 1 & 0 & 1 \\
\hline & $\begin{array}{l}\text { \% within } \\
\text { Gender }\end{array}$ & 0.30 & 0.0 & 0.20 \\
\hline \multirow{2}{*}{ Simple } & Count & 177 & 44 & 221 \\
\hline & $\begin{array}{l}\text { \% within } \\
\text { Gender }\end{array}$ & 49.40 & 47.8 & 49.1 \\
\hline \multirow{2}{*}{ Spiral } & Count & 0 & 1 & 1 \\
\hline & $\begin{array}{l}\text { \% within } \\
\text { Gender }\end{array}$ & 0.00 & 1.1 & 0.20 \\
\hline \multirow{2}{*}{ Total } & Count & 358 & 92 & 450 \\
\hline & $\begin{array}{l}\text { \% within } \\
\text { Gender }\end{array}$ & 100.0 & 100.0 & 100.0 \\
\hline
\end{tabular}

Interesting results are obtained while performing a cross abulation between the type of fracture and the gender Table 4). Simple fracture was dominant both in males Compound fracture showed the dominancy in female
gender (31.5\%). The remaining fractures were all higher in males. A Pearson Chil-square test was performed and fracture and gender $P=0.02(P<0.05)$ was obtained.

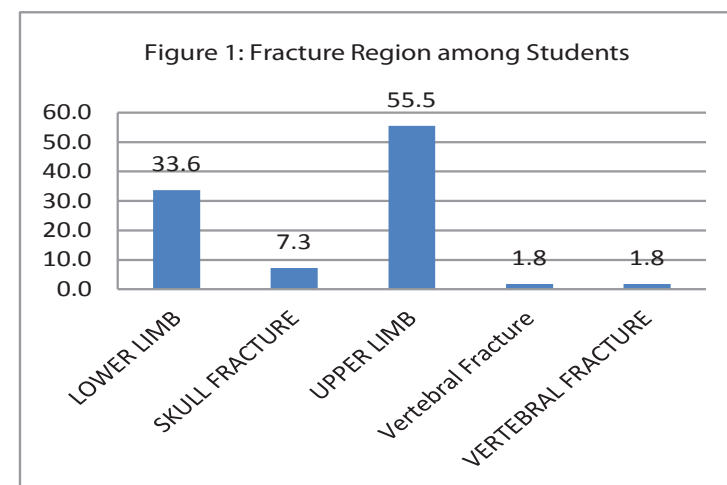

Figure 1 represents students were highest in the popula fion 110, interesting results were drawn from it. The prevacompared with lower extremity (33.6\%) and skul fracture compar.
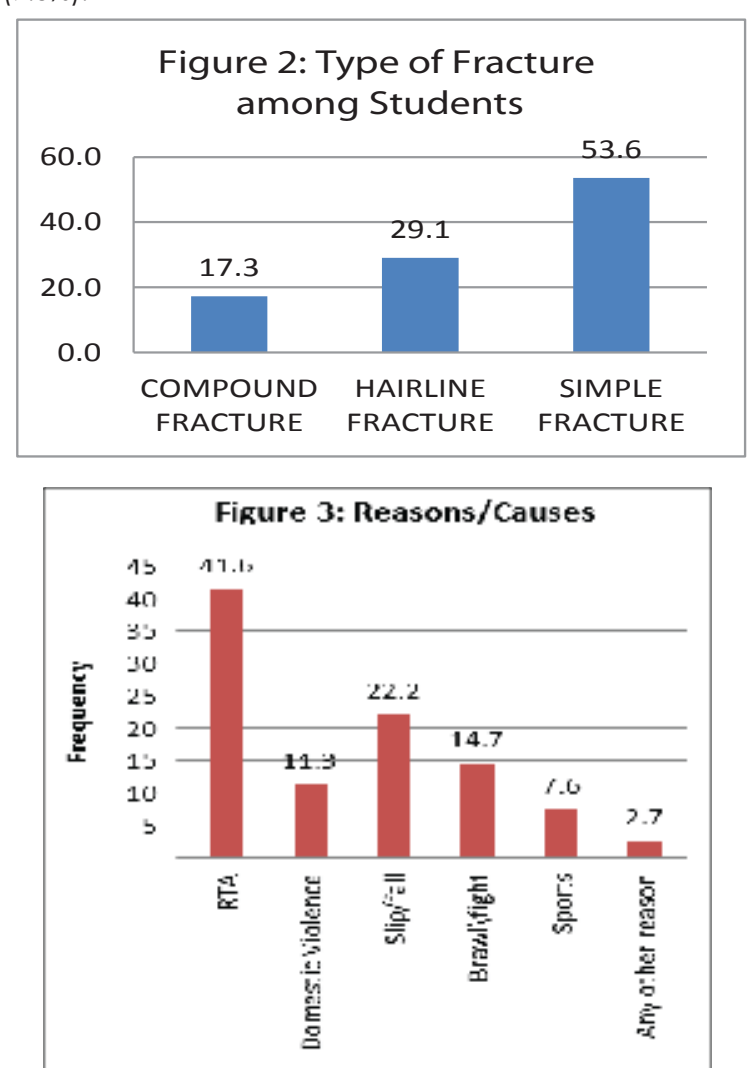
However simple fracture as being the highest in the After RTA fall brawl seems most common reasons. Study
also shows that most falls took place at home with hard flooring $38.9 \%$ osthers including wet area $9 \%$, rough
surface $29.3 \%$, and smooth surface $19.3 \%$ (Table 5, Figure

\begin{tabular}{|c|c|}
\hline Type of Flooring & $\mathrm{n}(\%)$ \\
\hline Bricks & $9(2.0)$ \\
\hline Cemented & $15(3.3)$ \\
\hline Grass & $6(1.3)$ \\
\hline Ground & $4(0.9)$ \\
\hline Hard & $175(38.9)$ \\
\hline Marble & $2(.4)$ \\
\hline Missing & $4(.9)$ \\
\hline Railway track & $1(0.2)$ \\
\hline Rough & $132(29.3)$ \\
\hline Sand & $4(0.9)$ \\
\hline Smooth & $87(19.3)$ \\
\hline Tiles & $7(1.6)$ \\
\hline Wet floor & $4(0.9)$ \\
\hline N & 450 \\
\hline Table 5: Shows the type of flooring \\
\hline
\end{tabular}

\section{History Of Disease}

\begin{tabular}{|l|c|}
\hline \multicolumn{2}{|l|}{} \\
\hline YES & $95(21.1)$ \\
\hline NO & $355(78.9)$ \\
\hline N & 450 \\
\hline Medicine & $80(17.8)$ \\
\hline YES & $370(82.2)$ \\
\hline NO & 450 \\
\hline N & $191(42.4)$ \\
\hline Smoking & $259(57.6)$ \\
\hline YES & 450 \\
\hline NO & $35(7.8)$ \\
\hline N & $258(57.3)$ \\
\hline Meat Intake & $14(3.1)$ \\
\hline DAILY & $143(31.8)$ \\
\hline FREQUENTLY & 450 \\
\hline NEVER & \\
\hline OCCASIONALLY &
\end{tabular}

able 6 shows only 20\% of women participated in the study but no significant changes were observed for calcium and vitamin $D$ levels between the genders.
However, good protein diet is one of the most important factor which can decrease the overall fracture ratio selected samples were showing following percentage of protein intake in their diet on daily bases; mill $32 \%$, eggs $14 \%$, meat $7.8 \%$. Although frequent intake of mik, meat, egg: $43.3 \%$ and meat: $57.3 \%$. $78.9 \%$ had no my previous 
history of any chronic disease and $82.2 \%$ of all not taking any medicine that may cause any adverse effects on

\section{DISCUSSION}

Fractures are the misfortune or unexpected event which
may cause life time problems. The basic focus of this study is to determine the expected and unexpected causes of fractures and their frequencies entering the ED. With the has affected the economy of both the developed and under developed countries. The motive of this study is to create awareness among the people about the cause in order causes of death and accounting for $5.2 \%$ of all mortality worldwide. It is a leading cause of death and disability for people under 45 years in the industrialized world. These important and a largely neglected health problem developing countries'

Road Traffic Accidents (RTAs) and injuries related to them upcoming world. Likewise, highest number of RTA; $48 \%$ were the causes of fractures entering the Emergency Department. Interestingly, the disproportionately hig to a significant extent, with greater exposure to driving as
well as to patterns of high risk behavior when driving. And
ratio of males to females is high. Unfortunately, Karachi is ratio of males to females is high. Unfortunately, Karachi facing one of the highest numbers of accidents in
Pakistan, especially due to bike riders, resulting in fatal Pakistan, especially due to bike riders, resulting in fata only fracture was part of this study so disability was not identified. Based on the facts and figures of accidents March 312013 , the report stated that 304 peoplan 1 an the accidents and 1,377 people received serious iniuries becoming almost paralyzed for life. "Of the total 304 fatalities, 48 per cent were pedestrians, 30 per cen motorcycle riders, 16 per cent passengers, and four per

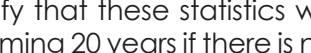
new commitment to prevention.

In a study conducted by Verma and Tewari in Delhi, total years $(69 \%$ that is 470 out of 680$)$. Similar results with different percentage were obtained in our study $202.12-24$ Moreover, students were the most vulnerable group in our
study (24.4\% i.e. 110 students out of 450 ). The reas (a) and most of them not following the traffic rules and others are unaware of it. On the other hand lower limb fracture

Previous researches have revealed violence as primarily
affecting fractures mostly due to partner violence. The magnitude of intimate partner vaitence in in Pakistan
mathe indicated that $44 \%$ of women experience lifetime marita physical abuse
represented in our study.

Moreover, violence against women is public health developing countries both. Muslim societies have an criticized for violating women right particularly. A study conducted by Fariyal et al, on the attitudes of Pakistan men towards abuse on wife and domestic violence punching and slapping, $8 \%$ fractures had sustained by heir wives as consequence of physical abuse $e^{26}$. Our study also reveals the nature of more serious fractures. The main eason of this violence is poverty frustration and depresSince Epidemiological studies suggest that lower
vitamin-D $\{25(\mathrm{OH}) \mathrm{D}\}$ status is associated with a higher risk for osteoporotic fractures, a study was conducted at various hospitals in Karachi from April 2007 to September $\mathrm{D}$ among healthy Pakistanis is high and duration of sun exposure is the most common predictor of it 27 . Although Vitamin D deficiency and low BMD value are the one of
the significant factors leading to fractures yet subject
selected in our study were unaware of this as $94.9 \%$ had no scan done. The reason behind it is assumed to be lack of education and the second reason is poor financial status. Advancing age, longer duration of menopause,
multi parity, low BMl, poor socioeconomic conditions were found to be significant risk factors in women presenting with hip fracture ${ }^{28}$. Our study indicates fall/fight as second most common cause of fracture. Falling on hard surface causes a serious head and lower limb vertebral fatal and cause life time disability.

Beside other important factors dietary component was populations are consuming low calcium diet and no supplements are added to them. Our study clearly shows that $81.7 \%$ of respondents do not use calcium supplemisk of fracture.

A study was conducted for traumatic spine fracture
ncidence in Tehran, Iran, was 16.35 (95\%Cl: $3.4-48.0)$ per incidence in Tehran, Iran, was 16.35 (95\%Cl: 3.4-48.0) per
$100.000^{29}$. The incidence of TSF in males was more than twice that of females ${ }^{29}$. A prospective study was conducted in Ethiopia aimed at determining the causes, magnifractures in adults. 422 orthopedic adult patients sustained a major fracture of their limbs. Mean age was
35 years with a male to female ratio was $3: 1$. Pathological fractures were encountered only in two $(0.5 \%)$ patients. Nearly $48 \%$ of the traumatic fractures were due to road traffic accidents. The highest freequency of fracture
occurred on the femur $(68,15 \%)^{9}$. Contrasting results occurred on the femur $(68,15 \%, "$. Contrasting results
were obtained while comparing to our present data
where higher frequency was obtained when compared with vertebral fractures.

Previously, a study was conducted to quantify the global where an estimated 9.0 million osteoporotic fractures of which 1.6 million were at the hip, 1.7 million at the forearm and 1.4 million were clinical vertebral fractures 30 . study.

A number of contrasting results were obtained in our basic reason was due to unequal gender difference
male: female $(4: 1)$. In addition, the study should be conducted on larger scale and higher sample size to

\section{CONCLUSION} Globally, the frequency of fractures is increasing with the
passage of time, cuasuing activity limitation and portici-
pant restriction. These are directly and indirectly affecting pant restriction.
the activities of daily living. Higher scale researches should be conducted identifying types of fractures in both the study. Awareness programs are essential in the lower socio-economical class to improve the
is beneficial to their bones and joints.

Besides this there should be policies about traffic safety and common man should be responsive towards illiteracy and causing domestic violence on females that needs to

REFERENCES

11] World Health Organization. Global burden of disease. Www.who.int/healthinfo/global_burden_disease/en/ (Accessed on May 01, 2010).

[2] Felliciano DV, Mattox K, Moore EE. Nauma, 6th

3] CDC. National estimates of the ten leading causes of nonfatal injuries, Centers for Disease Control and Prevention 2004. Www.cdc.gov/injury/Misqars.hth

Mackenzie EJ Rivera FP Jurkovich GJ The Nation Study on Costs and Outcomes of Trauma. J Trauma 2007;63:554.

[5] Gaffer A, Hyder AA, Masud TI. The burden of road al iniury survey of Pakistan. Public Hation2004; $118: 211$ - 7 .

[6] Singer MS, Gaffer A. Risk factors for road traffic injun in Pakistani children. $J$ Col Physicians surg Pak

7] Fikree FF, Jafarey SN, Korejo R, Afshan A, Durocher pregnancy: experiences of postpartum women in

8] Mehmood A, Razzak J, Khan S J. Blast injuries in Karachi. In: Health Sciences Research Assembly 2007, Abstract Book. The Aga Khan University,

[9] Chamberlain JM, Patel KM, Pollack MM. Recalibrafion of the pediatric risk of admission score using
multi-institutional sample. Ann Emerg Med 2004:43:461.

[10] Khosla S, Melton LJ 3rd, Dekutoski MB, Achenbach distal Oberg AL, Riggs BL. Incidence af childhood distal forearm fractures over 30 years: a popula
lon-based study. JAMA 2003:290:1479.

(11] Jónsson B, Bengnér U, Redlund-Johnell I, Johnell $O$ Forearm fractures in Malmö, Sweden. Changes in
the incidence occuring during the 1950s, 1980 s and
1990s. Acta Orthop Scand. 1999:70(2):129-32

[12] Jones IE, Williams SM, Dow N, Goulding A. How many children remain fracture-free during growth Aarticipating in the Dunedin Multidisciplinary Health and Development Study. Osteoporos int 2002;13(12):990-5.

(13] Carson S, Woolridge DP, Colletti J, Kilgore K. Pediatric upper extremity injuries. Pediatr Clin North Am
2006; 53(1):41-67.
[14] Della-Giustina K, Della-Giustina DA. Emergency Department evaluation and treatment of pediatric
thopedic injuries. Emerg Med Clin North Am orthopedic injuries. Emerg Med Clin North Am
1999;17(4):895-992.

[15] Frost HM, Schönau E. The "muscle-bone unit" in children and adolescents: a 2000 overview.
Pediatr Endocrinol Metab 2000; $13(6): 571-90$.

16] Specker BL, Brazerol W, Tsang RC, Levin R, Searcy Steichen J. Bone mineral content in children 1 to 6
years of age. Detectable sexdifferences after 4 years of age. Detectable sexdifferences
years of age. Am I Dis Child 1987;141:343

[17] American Academy of Orthopaedic Surgeons. Number (in thousands) of emergency department
visits for fracture: 2006 . http://www coss search/stats/ER_Visits Fracture.pdf. Accessed July 28,2009

[18] Chung KC, Spilson SV. The frequency and epidemiology of hand and forearm fractures in the United
States. $J$ Hand Surg $A m$ 2001:26

[19] Admasie D, Tekle YY, Wamisho BL Radiological and Clinical Details of Major Adult Limb Fractures in a
Teaching Hospital, AAU, Ethiopia. ECAJS Teaching Hospital, AAU, Ethiopia. ECAJS
March-April 2009;14(1):88-97

[20] Jha N, Agarwal Ch. Epidemiological Study of Road Traffic Accident Cases: ASt From E a s t e r $n$
Nepal. Regional Health Forum, WHO South-East Asia region 2004:8(1):15-22

[21] Jha N. Road traffic accidents case sat BPKIHS, Dhahran, Nepal: One year in retrospect. J Nep Med

122] Mehta SP. An enidemiological study of road traffic accident Cases admitted in Safdar jang Hospital

23] Ghosh PK. Epidemiological study of the victims of vehicular ac- accidents in Delhi. JIMA

1992:90(12):309-312
[24] Verma PK, Tivari KN. Epidemiology of Road Traffic
injuries in. Delhi: result of a Survey, regional Health injuries in Delhi: result of a Survey. regional Heall
Forum, wHO South-East Asia region 2004:8:(1):1-10

(25] Singer MS, Gaffer A. Risk factors for road traffic injury
in Pakistani children. J Coll Physicians Surg Pak in Pakistani chi
2004; $14: 709-12$

[26] Fikree FF, Razzak JA, Durocher J. Attitudes of 27] Mahmood K, Akhtar ST, Talib A, Haider I. Vitamin-D status in a Population of Healthy Adults in Pakistan.

[28] Mamgi MF, Hasan JA, Sabri MS. Risk Factors for
Osteoporosis in Post- Menopausal Women with Hip Osteoporosis in Post- Mril-June 2010:15(2):82-86
Eractures. JSP (Int) April

[29] Moradi-Lakeh M, Rasouli MR, Vaccaro AR, Saadat S, spine fractures in Tehran, Iran. BMC Public Health 2011;11:789. doi: 10.1186/1471-2458-11-789

[3] Johnell $\mathrm{O}$, Kanis JA. An estimate of the worldwide prevalence
porotic 2006;17(12):1726-1733. 